\title{
Integrative Gastroenterology and Hepatology
}

\section{Endoscopy lists Distribution between Medical and Surgical Gastroenterology: What's The Impact on Work Force?}

\author{
Mahmood $\mathbf{T}^{* *}$ and Shoaib $\mathbf{M}^{2}$ \\ ${ }^{1}$ Consultant Gastroenterologist, National Health Service, United Kingdom \\ ${ }^{2}$ Gastroentrology Middle Grade, United Kingdom
}

*Correspondence: Tariq Mahmood, Consultant Gastroenterologist, National Health Service, Gastroenterology, 92 Long Lane, Ickenham, Middsx, UB108sx, United Kingdom, Tel: +447956984625; E-mail: tm123@btinternet.com

Received: June 25, 2018; Accepted: July 23, 2018; Published: July 28, 2018

\section{Abstract}

Background: Minimum number of endoscopic procedures must be done to maintain accreditation as an endoscopist.

Aims and Objectives: This study aimed to look at the general distribution of endoscopic procedures amongst physician gastroenterologists and the surgeons in a sample district hospital of United Kingdom. It would then infer what impact this could have on the work force.

Methods: Prospective study recruited all endoscopy done in a district general hospital of United Kingdom for 90 days.

Results: Physicians had 30\% less lists while Surgeons had $47.5 \%$ more lists according to the eligibility criterion of two lists per consultant per week.

Conclusion: Predominance of surgeons doing procedures in endoscopy has a potential of having a direct impact on training of medical gastroenterologists, service delivery and recruitment. Authorities must find correct balance of medical and surgical lists in endoscopy for a cost effective and clinically effective service.

\section{Background}

Any hands on skill will require continued practice to maintain capability and an enhanced competence [1]. In the aviation industry as an example, the pilots must do a certain minimum number of hours of flying each year to maintain their license. Similarly to maintain clinical skills, doctors must see certain number of specific kind of patients. This can be done through normal inpatient and outpatient as well as surgical lists or systematic training. Even computer games have been evaluated for the purpose of learning surgical skills. It has been argued that both blended and interactive learning from serious digital games can be used in learning technical and non- technical skills [2]. According to British Society of Gastroenterologists (BSG) guidelines, all endoscopists must keep up their skills by doing sufficient number Int Gast Hepatol, 1(1): 42-45 (2018) of procedures every year. Minimum of 100 OGD, 200 colonoscopies, and 200 ERCPs per year are deemed necessary to be safe in endoscopy skills. In order to maintain endoscopic accreditation, the operators must demonstrate having done these minimum numbers of procedures. To achieve the required numbers, the endoscopy department must have the capacity to provide sufficient patients for endoscopy. There should be a smooth list of patients throughout the year in a formative manner rather than a summative collection for an intense period to just tick box the check lists. Furthermore, the endoscopy department must have a fair distribution of cases amongst medical and surgical specialist endoscopists to provide opportunities to maintain skills. 
A Consultant must have at least two endoscopy lists per week to maintain the core skills.

\section{Aims and Objectives}

This study aims to analyze the distribution of OGD's and colonoscopies amongst medical and surgical specialties in a fully JAG accredited endoscopy department of a sample district hospital in the United Kingdom. The objective were to study; whether Medical or Surgical specialty is mainly doing endoscopy and therefore what are the training needs of each specialty? Whether minimum requirement for keeping skills of all endoscopists' up to date are being met? Are there sufficient numbers of OGD's and colonoscopies in an individual's list? Is the skill maintenance a formative or summative process?

\section{Methods}

Data was collected retrospectively from endoscopy department of a sample district general hospital. Total of 4 months data was collected from 1/1/2017 till 30/4/2017. Only Endoscopy lists in one district hospital were included in the study. The lists were collated according to the operator as well as the number of procedures done in each list. Analysis was done by cross tabulation and noting the trends. The hospital had 3 physician and 2 surgical gastroenterology consultants. It was expected that each medical gastroenterology consultant must have 2 weekly endoscopy lists and therefore there should be 6 medical and 4 surgical lists each week for the 3 Physicians and 2 surgical Consultants. Thus in our study period of 16 weeks the 3 medical gastroenterologists consultants should have $16 \times 6=96$ lists. The 2 surgical consultants should have $16 \times 4=64$ lists.

\section{Results}

A total of 180 lists took place in 90 days. All urology lists as well as (TOE) Trans-esophageal Echocardiography lists were excluded from the study. Table 1 shows all the endoscopy lists done and what procedures were undertaken as well as the professional nature of the operator.

Our data showed that Physicians had 58 lists only instead of 96 . This is $30 \%$ less than the expected. Surgeons had 122 lists instead of 64 . This is $47.5 \%$ more than expected. Furthermore, medical gastroenterologists had an average of 5.0 procedures in a list while the surgeons had 6.4 procedures per list. One surgeon had three times more colonoscopy in the list than the medical gastroenterologist who was doing grade 4 polypectomy and would require more case volume to keep his hands on skills. Figure 1 below shows the distribution of endoscopy lists according to different procedures in a cumulative manner.

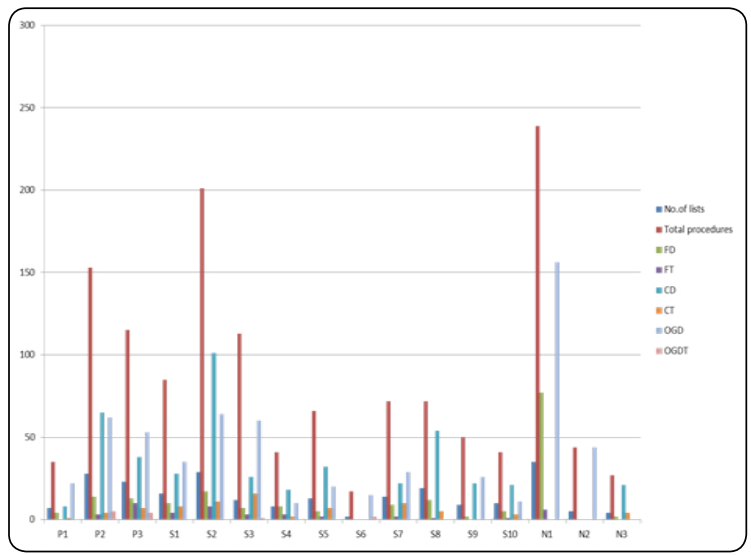

$\mathrm{P}=$ Physician gastroenterologist $\mathrm{S}=$ Surgeon, $\mathrm{N}=$ Nurse, $\mathrm{FD}=$ Flexi-sig diagnostic, FT=Flexi sig therapeutic, $\mathrm{CD}=$ Colonoscopy diagnostic, $\mathrm{CT}=$ Colonoscopy therapeutic, OGD=gastroscopy diagnostic, OGDT=Gastroscopy therapeutic

Figure 1: Number of different procedures done by individual Physician Gastroenterologists, Surgeons and Nurse practitioners

Figure 2 below shows the different professionals and number of lists done by each.

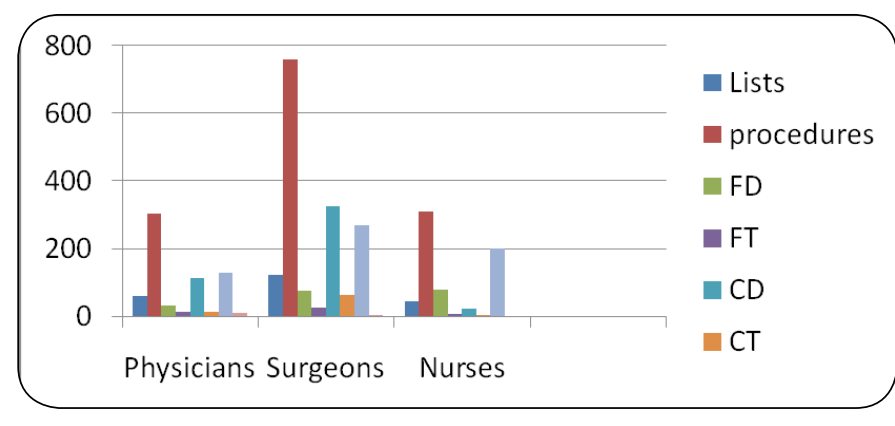

$\mathrm{P}=$ Physician gastroenterologist $\mathrm{S}=$ Surgeon, $\mathrm{N}=$ Nurse, $\mathrm{FD}=$ Flexi-sig diagnostic, FT=Flexi sig therapeutic, $\mathrm{CD}=$ Colonoscopy diagnostic, $\mathrm{CT}=$ Colonoscopy therapeutic, OGD=gastroscopy diagnostic, OGDT=Gastroscopy therapeutic

Figure 2: Total number of Procedures done by Physician Gastroenterologists, Surgeons and Nurse Practitioners.

Physician Gastroenterologists did 303 procedures, Surgeons 758 and Nurses 308 procedures in total. Figure 3 shows the total of endoscopy lists done according to individual operators. 
Table 1: Number of lists done by Physicians, Surgeons and Nurse Endoscopists according to procedure type.

\begin{tabular}{c|c|c|c|c|c|c|c|c}
\hline Endoscopist & No.of lists & Total procedures & FD & FT & CD & CT & OGD & OGDT \\
\hline PI & 7 & 35 & 4 & 0 & 8 & 1 & 22 & 0 \\
\hline P2 & 28 & 153 & 14 & 3 & 65 & 4 & 62 & 5 \\
\hline P3 & 23 & 115 & 13 & 10 & 38 & 7 & 53 & 4 \\
\hline SI & 16 & 85 & 10 & 4 & 28 & 8 & 35 & 0 \\
\hline S2 & 29 & 201 & 17 & 8 & 101 & 11 & 64 & 0 \\
\hline S3 & 12 & 113 & 7 & 3 & 26 & 16 & 60 & 1 \\
\hline S4 & 8 & 41 & 8 & 3 & 18 & 2 & 10 & 0 \\
\hline SS & 13 & 66 & 5 & 2 & 32 & 7 & 20 & 0 \\
\hline S6 & 2 & 17 & 0 & 0 & 0 & 0 & 15 & 2 \\
\hline S7 & 14 & 72 & 9 & 2 & 22 & 10 & 29 & 0 \\
\hline SS & 19 & 72 & 12 & 1 & 54 & 5 & 0 & 0 \\
\hline S9 & 9 & 50 & 2 & 0 & 22 & 0 & 26 & 0 \\
\hline SIO & 10 & 41 & 5 & 1 & 21 & 3 & 11 & 0 \\
\hline N1 & 35 & 239 & 77 & 6 & 0 & 0 & 156 & 0 \\
\hline N2 & 5 & 44 & 0 & 0 & 0 & 0 & 44 & 0 \\
\hline N3 & 4 & 27 & 2 & 0 & 21 & 4 & 0 & 0 \\
\hline
\end{tabular}

$\mathrm{P}=$ Physician gastroenterologist, $\mathrm{S}=$ Surgeon, $\mathrm{N}=$ Nurse, $\mathrm{FD}=\mathrm{Flexi}$-sig diagnostic, $\mathrm{FT}=\mathrm{Flexi}$ sig therapeutic, $\mathrm{CD}=\mathrm{Colonos}-$ copy diagnostic, $\mathrm{CT}=$ Colonoscopy therapeutic, OGD=gastroscopy diagnostic, OGDT=Gastroscopy therapeutic

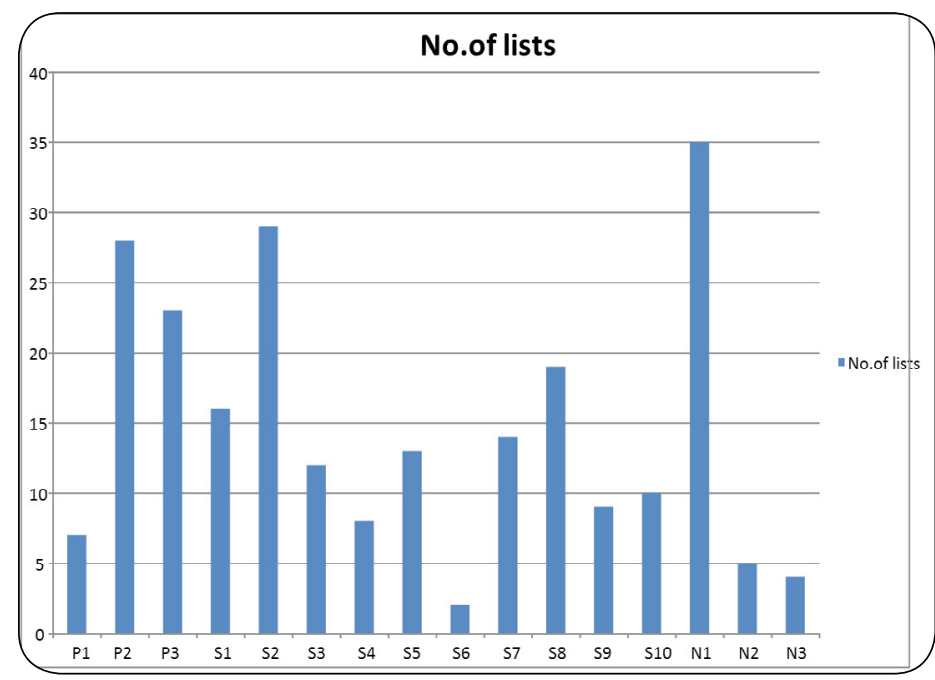

$\mathrm{P}=$ Physician Gastroenterologist, $\mathrm{S}=$ Surgeon, $\mathrm{N}=$ Nurse Practitioner

Figure 3: Total number of lists done by individual Physician Gastroenterologists, Surgeons and Nurse Practitioners.

Two most important procedures in this context are gastroscopy and colonoscopy. Gastroscopy is a very commonly done procedure. Colonoscopy requires more therapeutic skills as polypectomy may be needed. It is expected that polyps will be detected in no less than

Int Gast Hepatol, 1(1): 42-45 (2018)
$20 \%$ of colonoscopy procedures done. Hence one fifth at least will need therapeutic intervention. Therefore hands on skill maintenance are particularly important in colonoscopy. Figure 4 below shows OGD and figure 5 shows colonoscopy procedures done by individual operators.

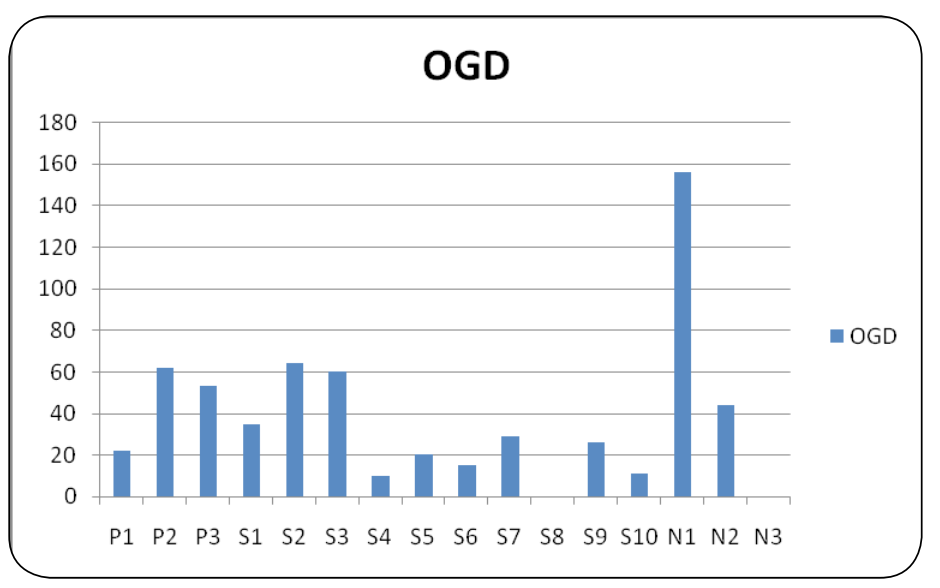

$\mathrm{P}=$ Physician Gastroenterologist, $\mathrm{S}=$ Surgeon, $\mathrm{N}=$ Nurse Practitioner

Figure 4: Number of Gastroscopy done by Physician Gastroenterologist, Surgeon and Nurse Practitioners.

\section{Discussion}

Our data showed that the procedural efficiency 
for medical gastroenterologists was low due to less number of the lists done by them as well as the number of procedures booked in each list. There seemed over subscription to surgical department and thus an unequal distribution of endoscopic work between medical and surgical gastroenterologists. This can lead to lack of formative process in maintaining skills in endoscopy. Furthermore training needs of individual specialties can only be met by having adequate number of lists and proper filling of endoscopy lists.

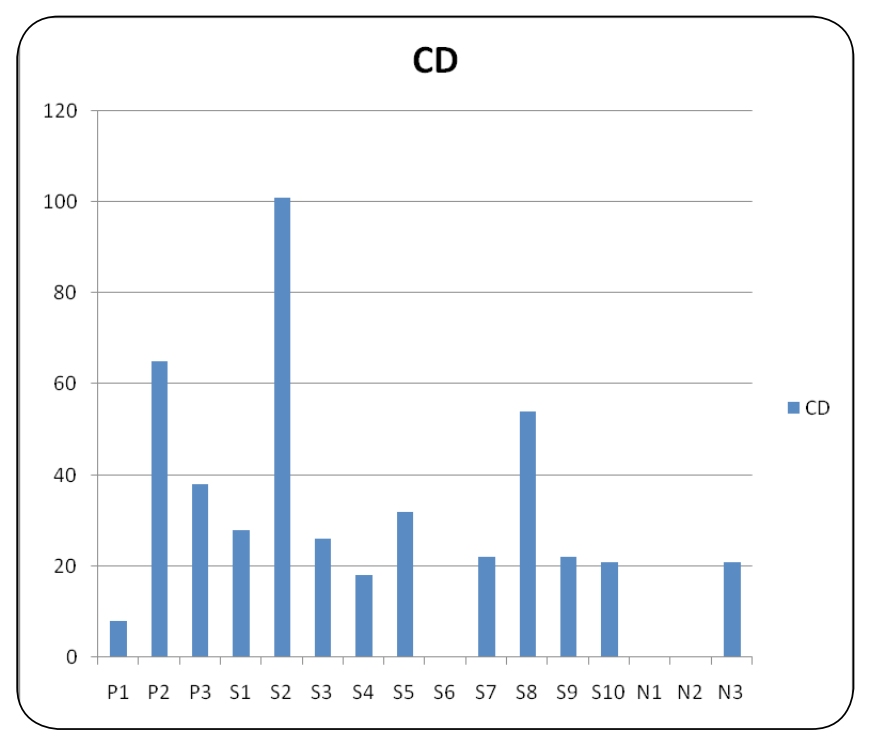

Figure 5: Number of Diagnostic Colonoscopy done by Physician Gastroenterologist, Surgeon and Nurse Practitioners.

There should be a fair distribution of lists and number of procedures in each list so that each endoscopist can fulfill the Joint Advisory Group (JAG) criteria for minimum OGD's and colonoscopies to be done every year. Unfair distribution can cause stress to the endoscopists for they must meet certain numbers to stay accredited.

The limitation of the study is that it is based in only one district hospital of the United Kingdom. Further studies are warranted in other hospitals of the country in order to evaluate the nature of impact it has on the endoscopy work force.

Surgeons would logically be expected to do more surgical procedures rather than endoscopy and their trainees would be expected to concentrate more on operating theatre procedures instead of endoscopy. One drawback of surgeons doing more endoscopy lists is that the physician gastroenterology trainees may not get as many opportunities to get trained in endoscopy in good time to take up responsibility as consultants.

There is need that all hospitals should evaluate the situation of endoscopy lists locally and achieve fair distribution between physicians and surgeons. This will enable appropriate training as well as maintenance of endoscopic skills of both physician gastroenterologists and the surgeons. It would also be a more cost and clinical effective way of resource utilization for the hospitals.

\section{References}

1. Graafland M, Schraagen JM, Schijven MP. Systematic review of serious games for medical education and surgical skills training. British Journal of Surgery. 2012;99(10):1322-1330. doi: http://dx.doi. org/10.1002/bjs.8819

2. Moulton C-AE, Dubrowski A, MacRae H, Graham B, Grober E, Reznick R. Teaching Surgical Skills: What Kind of Practice Makes Perfect?: A Randomized, Controlled Trial. Transactions of the . Meeting of the American Surgical Association. 2006;124:66-75. doi: http:// dx.doi.org/10.1097/01.sla.0000234808.85789.6a

\section{@Gratis}

Copyright: (c) Mahmood et al. This is an Open Access article distributed under the terms of the Creative Commons Attribution License, which permits unrestricted use, distribution, and reproduction in any medium, provided the original work is properly cited. 